\title{
Competitive Phenomenon of Hydrogen Trapping and Carbon Segregation in Dislocations Introduced by Drawing or Martensitic Transformation of 0.35 mass $\%$ and 0.8 mass $\%$ C Steels
}

\author{
Daisuke HIRAKAMI, ${ }^{1,4) *}$ Shingo YAMASAKI, ${ }^{1)}$ Toshimi TARUI ${ }^{2)}$ and Kohsaku USHIODA ${ }^{3,4)}$ \\ 1) Bar \& Wire Rod Reseach Lab., Steel Research Laboratories, Nippon Steel \& Sumitomo Metal Corporation, 1 Kimitsu, \\ Kimitsu City, Chiba, 299-1141 Japan. $\quad$ 2) Muroran Div., Nippon Steel \& Sumikin Technology Corporation, 12 Nakamachi, \\ Muroran City, Hokkaido, 050-0087 Japan. $\quad 3)$ Technical Research \& Development Bureau, Nippon Steel \& Sumitomo \\ Metal Corporation, 20-1 Shintomi, Futtsu City, Chiba, 293-8511 Japan. 4) Graduate School of Natural Science and Tech- \\ nology, Kanazawa University, Kadomamachi, Kanazawa City, Ishikawa, 920-1192 Japan.
}

(Received on September 30, 2015; accepted on November 12, 2015; originally published in Tetsu-toHagané, Vol. 100, 2014, No. 10, pp. 1322-1328)

\begin{abstract}
Hydrogen embrittlement has become a crucial issue with the promotion of high-strength steel. Many studies have been conducted on the mechanism of hydrogen embrittlement. Because the elucidation of the state of hydrogen is important to understand the mechanism, the states of hydrogen in the steels investigated were controlled. In the present study, 0.35 mass \% C and 0.8 mass \% C steels annealed in the hydrogen atmosphere followed by quenching from the austenite region together with drawn pearlitic steel of 0.8 mass \% C were used to analyze the state of the hydrogen contributing to the emission peak, in particular, at about $300^{\circ} \mathrm{C}$ in the Thermal Desorption Analysis (TDA) curve. The peak at $300^{\circ} \mathrm{C}$ was significant for quenched 0.8 mass \% C steel with low Ms temperature; however, the peak decreased with aging at room temperature. However, in 0.35 mass \% C steel with high Ms temperature, the peak at $300^{\circ} \mathrm{C}$ was no longer observed. Moreover, in the hydrogen charged as drawn 0.8 mass \% pearlitic steel, the peak at $300^{\circ} \mathrm{C}$ did not change with aging at room temperature because of no significant carbon in solid solution, while the peak at $100^{\circ} \mathrm{C}$ decreased with the increase in aging time. Taking into account the competitive phenomenon of hydrogen trapping at the dislocation core and $\mathrm{C}$ segregation to dislocations during room temperature aging or during quenching from Ms temperature, it was concluded that the hydrogen peak at about $300^{\circ} \mathrm{C}$ is hydrogen trapped in the dislocation core, while the other hydrogen peak at $100^{\circ} \mathrm{C}$ is attributed to the hydrogen trapped by the stress field generated by dislocation.
\end{abstract}

KEY WORDS: hydrogen embrittlement; delayed fracture; hydrogen analysis; hydrogen trapping site; high strength steel.

\section{Introduction}

Hydrogen embrittlement has become a crucial issue with the promotion of high strength steel. Many studies have been conducted on the mechanism of hydrogen embrittlement. In general, hydrogen embrittlement occurs when the intrusion amount of hydrogen from the environment into steel exceeds the critical diffusible hydrogen quantity. ${ }^{1)}$ Here, 'the critical diffusible hydrogen quantity' is the hydrogen quantity which depends on the strength level of steel, stress condition and so on, and hydrogen embrittlement occurs when diffusible hydrogen existing in the material exceeds this value. Existing sites of hydrogen in steel are known such as interstitial site, vacancy, void, dislocation and the interface between precipitate and matrix. ${ }^{2-4)}$ Hydrogen existing in interstitial site diffuses readily in room temperature. For example, it is known that, under tensile stress, diffusion

* Corresponding author: E-mail: hirakami.9fc.daisuke@jp.nssmc.com DOI: http://dx.doi.org/10.2355/isijinternational.ISIJINT-2015-555 and aggregation of hydrogen occurs nearby the prior austenite grain boundary of medium-carbon martensitic steel and causes the degradation of grain boundary strength and hydrogen embrittlement. Because the hydrogen is trapped in the interface between fine precipitate and matrix due to the stress field which makes its diffusion difficult, it is in general considered to be harmless. Much the same is true on the hydrogen trapped in void. On the other hand, hydrogen interacts with vacancy and dislocation. That is, hydrogen is thought to stabilize the vacancy created by plastic deformation. ${ }^{5)}$ In addition, hydrogen is thought to be trapped in the stress field generated by dislocation or in the dislocation core. $^{5-7)}$ As stated above, various trap sites exist in steel, therefore it is important to elucidate the site of hydrogen in steel, that is, its existing state in order to discuss hydrogen embrittlement.

As a macroscopic method to understand the existing state of hydrogen, Thermal Desorption Analysis (TDA) is well known. ${ }^{8)}$ Moreover, recently the direct observation of hydrogen trapped in the interface between fine $\mathrm{TiC}$ and 
matrix using Three Dimensional Atom Probe (3DAP) has also been reported. ${ }^{9)}$ However, in regard to hydrogen trapping by lattice imperfection for which direct observation is generally difficult, detailed study is not conducted and many aspects are still unclear.

Takai et al. applied wire-drawing to pure iron and demonstrated that the quantity of trapped hydrogen during hydrogen charge had increased with wire-drawing strain. ${ }^{10)}$ It was explained that the number of hydrogen trapping sites such as dislocation and vacancy cluster had increased with the increase of wire-drawing strain. However, details of the hydrogen trapping status by dislocation were not clarified.

Matsui et al. conducted hydrogen charge during tensile testing using high-purity single-crystal iron. Because of the presence of hydrogen, softening was observed in highpurity iron. ${ }^{11)}$ The reason was presumed to be the increase of mobility of screw dislocation. On the other hand, Asano et al. conducted hydrogen charge during tensile testing using high-chromium steel, and hardening was observed with the presence of hydrogen. ${ }^{12)}$ The reason for hardening was presumed to be solid solution strengthening by hydrogen.

Nagumo et al. conducted a three-point bending test after hydrogen charge using extra-low carbon steel and demonstrated the degradation of ductile crack propagation resistance with the presence of hydrogen. ${ }^{13)}$ As the reason, it was presumed that, because the vacancies formed during the bending test by interaction between dislocations were stabilized by hydrogen, ductile crack propagation resistance had decreased. Enomoto et al. ${ }^{7,16)}$ evaluated the prediction of TDA-curve of high strength martensitic steel by incorporating the $\mathrm{C}$-segregation theory to dislocation ${ }^{15)}$ into the McNabb-Foster equation. ${ }^{14)}$ As a result, by experiments and computer simulations, it was demonstrated that the two peaks observed in TDA-curve consist of a first peak which appeared at around $100^{\circ} \mathrm{C}$ trapped by the stress field generated by dislocation and a second peak which appeared at around $300^{\circ} \mathrm{C}$ trapped by dislocating core. However, the study is centered on computer simulations, and it seems that there is still room for experimental verification.

As the effect of hydrogen on dynamic behavior of dislocation, the Hydrogen Enhanced Localized Plasticity (HELP) theory, ${ }^{17)}$ i.e. the mobility of dislocation is enhanced by hydrogen, is well known. As the mechanism, the model of solute hydrogen, creating an atmosphere around dislocation, mitigating the stress field and reducing interaction between dislocation and obstacles, is being considered. On the other hand, Taketomi et al., utilizing the first-principle calculation, evaluated the energy barrier required for motion of edge dislocation in $\alpha$-iron using the Nudge Elastic Band (NEB) method. ${ }^{18)}$ As the result, both increase (softening) and decrease (hardening) of mobility of dislocation are predicted depending on applied stress with low hydrogen concentration, and hardening is predicted with high hydrogen concentration.

As described above, though there are various arguments related to hydrogen trapping sites and the interaction between hydrogen and dislocation, it is important to understand the relation between hydrogen and dislocation which dominates plastic deformation, i.e. one of the elementary processes of fracture.

As medium-carbon steel for machine structure part usage, martensitic structure is the typical structure for high strength steel, into which highly dense dislocation is introduced by martensitic transformation during quenching. Moreover, with high-carbon steel wire, dislocation is introduced by the drawing process of wire. It is presumed that such dislocation introduced during quenching or plastic deformation interacts with hydrogen under stress. On the other hand, in the presence of solute carbon, hydrogen trapping to dislocation and carbon segregation to dislocation are expected to be competitive. Hagi et al. used extra-low carbon steel and presumed that the competition of segregation to dislocation between hydrogen and carbon took place in the stress field generated by dislocation judging from the changes in aging property and hydrogen permeation characteristic after plastic deformation. ${ }^{19)}$ However, since the aging characteristic is influenced by not only the stress field generated by dislocation but also the dislocation core, the relation in regard to the competitive phenomenon at the dislocation core has not been clarified yet. Therefore, in order to understand hydrogen embrittlement, it is important to promote better understanding of a more detailed experiment in regard to the state of hydrogen around dislocation.

Accordingly, in the present study, for the purpose of better understanding of the interaction between dislocation and hydrogen taking carbon segregation to dislocation into consideration, the following two examinations were performed. The first was to examine the interaction between dislocation introduced by martensitic transformation and hydrogen during quenching using steels with two different carbon contents. Since $M s$ temperature strongly depends on carbon content, the diffusion of hydrogen and carbon to dislocation during the cooling process may be influenced by $M s$ temperature together with, aging time at room temperature after quenching. The second was to clarify the state of hydrogen, and the interaction between hydrogen or carbon and dislocation. The interaction between dislocation introduced by the drawing process and hydrogen was examined by aging specimens for different times at room temperature. Taking the cause of hardness change with aging at room temperature into consideration, the validity of the trapping mechanism of hydrogen by dislocation was tested in a comprehensive manner.

\section{Experiment}

\subsection{Specimen}

High-carbon steel SWRS82B (0.8 mass\% C steel) and SCM435 (0.35 mass\% C steel) were used. As for SWRS82B, billet with $122 \mathrm{~mm} \times 122 \mathrm{~mm}$ section was heated to $1100^{\circ} \mathrm{C}$, then hot-rolled to $\phi 12 \mathrm{~mm}$ and $\phi 5.5 \mathrm{~mm}$. The rolled material had pearlitic structure. On the other hand, as for SCM435, commercial product with $\phi 5.0 \mathrm{~mm}$ was used, consisting of ferrite with spherical cementite as a second phase. Chemical compositions of the materials are shown in Table 1.

\subsection{Electrolytic Hydrogen Charge at Room Tempera- ture to Drawn-wire Material}

To examine the change of existing state of hydrogen in drawn wire pearlitic steel, $\phi 12 \mathrm{~mm}$ SWRS82B was drawn to $\phi 5.0 \mathrm{~mm}$ (reduction area $79 \%$ ) at room temperature and 
Table 1. Chemical compositions of steels used (mass\%).

\begin{tabular}{cccccccccc}
\hline & $\mathrm{C}$ & $\mathrm{Si}$ & $\mathrm{Mn}$ & $\mathrm{P}$ & $\mathrm{S}$ & $\mathrm{Cr}$ & $\mathrm{Mo}$ & $\mathrm{N}$ & $\mathrm{O}$ \\
\hline SWRS82B & 0.82 & 0.19 & 0.75 & 0.017 & 0.015 & - & - & 0.0035 & 0.0015 \\
SCM435 & 0.35 & 0.21 & 0.73 & 0.016 & 0.012 & 1.01 & 0.19 & 0.0039 & 0.0012 \\
\hline
\end{tabular}

cut to $100 \mathrm{~mm}$ in length, then cathodic hydrogen charge was conducted. The condition of cathodic hydrogen charge was to fill a glass container with $500 \mathrm{ml}$ of 3 mass\% $\mathrm{NaCl}+3 \mathrm{~g} / 1 \mathrm{NH}_{4} \mathrm{SCN}$ solution, to place $\phi 5.0 \mathrm{~mm}$ platinum wire gyroidally inside, and to dip the specimen in the center. By connecting this platinum wire to the anode and the specimen to the cathode, current was applied so that the current density was $0.2 \mathrm{~mA} / \mathrm{cm}^{2}$ with respect to the surface area of the specimen, and hydrogen charge was conducted at room temperature. Duration of hydrogen charge was 18 hours, and after the hydrogen charge was finished, acetone cleaning by ultrasonic cleaner for two minutes and drying were conducted. Two kinds of specimens, one cooled in liquid nitrogen immediately after drying and another left in the atmosphere for longest one month at room temperature and then cooled in liquid nitrogen were prepared, both of which had been stored in liquid nitrogen until hydrogen analysis was conducted.

\subsection{Hydrogen Charge by Hydrogen Atmosphere Heat- ing}

To examine the change of existing state of hydrogen at room temperature intruded into steel at high temperature, $\phi 5.0 \mathrm{~mm} \times 100 \mathrm{mmL}$ SCM435, and SWRS82B ground from $\phi 5.5 \mathrm{~mm} \times 100 \mathrm{~mm}$ to $\phi 5.0 \mathrm{~mm}$ were used to conduct the following heat treatment. After heating for one hour at $950^{\circ} \mathrm{C}$ under hydrogen atmosphere of 1 atm in the laboratory, oil quenching was performed. After heating for one hour at $950^{\circ} \mathrm{C}$, with the wire of $\phi 5.0 \mathrm{~mm}$ diameter, the hydrogen amount contained in the steel is considered to be saturated with the hydrogen amount which balances with partial pressure of hydrogen (about 3 mass ppm). Immediately after oil quenching, the specimen was ground with emery paper until metallic luster appeared in order to remove adhered substances on the surface. SWRS82B was left immediately after grinding at room temperature for 1, 2 and 4 weeks, then hydrogen analysis and hardness measurement were conducted. SCM435 was left immediately after grinding at room temperature for 1, 2, 4 and 7 days, then both hydrogen analysis and hardness measurement after 1 , 2, 4 and 7 days were conducted. By using a Vickers hardness meter, hardness was measured at four points which are the halfway points between the surface and center $(1 / 4 \mathrm{~d})$ for each right angle of channel section and at one point at the center, and their average was used as the representative value.

\subsection{Analytical Method of Hydrogen Content in Steel}

Hydrogen analysis was conducted by means of TDA method using gas chromatography. Prior to the measurement, a rod-shaped specimen of $\phi 5.0 \mathrm{~mm} \times 100 \mathrm{mmL}$ was ultrasonic-cleaned with acetone, dried and inserted into a silica tube in a furnace, then the measurement started after the completion of replacement by carrier gas. It took about 12 minutes from acetone cleaning to start of the measurement. The heating rate was $100^{\circ} \mathrm{C}$ /hour and the measurement was performed up to $800^{\circ} \mathrm{C}$. In addition, in order to subtract the background which occurs on the high temperature side, heating analysis was performed after the measurement leaving the specimen inside and under the same conditions. The balance of the first and second analyses results at each measured temperature was used as the measured value.

\section{Result}

\subsection{Change of Hydrogen Existing State in Drawn-wire Pearlitic Steel}

The hydrogen TDA curve of drawn-wire of SWRS82B (0.8 mass \% C steel) charged with electrolytic hydrogen and aged at room temperature is shown in Fig. 1. Immediately after hydrogen charge, the first peak of hydrogen around $100^{\circ} \mathrm{C}$ and a second peak around $300^{\circ} \mathrm{C}$ were observed. However, after aging for one month, while the first peak of hydrogen almost disappeared, hardly any change was observed with the second peak. According to Enomoto et $\left.a l .{ }^{7}\right)$ because the hydrogen of the first peak was trapped in the stress field generated by dislocation, therefore trapped with weak force, such hydrogen was considered to have diffused during the aging at room temperature and disengaged from the surface layer of the specimen. On the other hand, hydrogen of the second peak at higher temperature was, according to Enomoto et al., ${ }^{7)}$ considered to be the hydrogen trapped by the dislocation core. Interaction between the dislocation core and hydrogen is strong, therefore it was presumed that hydrogen continued to be trapped in the dislocation core at room temperature and no change of hydrogen amount was observed.

\subsection{Change of Hydrogen Existing State in Hydrogen Atmosphere As-quenched 0.8 mass\% C Steel}

The hydrogen TDA curve of SWRS $82 \mathrm{~B}$ ( 0.8 mass $\% \mathrm{C}$ steel) annealed at $950^{\circ} \mathrm{C}$ in hydrogen atmosphere of $1 \mathrm{~atm}$, followed by oil quenching and aging at room temperature, are shown in Fig. 2. With 0.8 mass $\% \mathrm{C}$ steel and immediately after quenching, the first peak of hydrogen at $100^{\circ} \mathrm{C}$ and a second peak at $300^{\circ} \mathrm{C}$ were observed. However, after aging for one week, hydrogen of the first peak as well as the second peak showed significant decrease, which was a very different behavior from drawn-wire pearlitic steel with 0.8 mass $\% \mathrm{C}$ shown in Fig. 1.

Changes in hardness with aging time at room temperature of SWRS82B ( 0.8 mass\% C steel) annealed at $950^{\circ} \mathrm{C}$ in hydrogen atmosphere of $1 \mathrm{~atm}$ followed by oil quenching is shown in Fig. 3. Hardness had significantly increased after aging at room temperature for one week, which suggests that carbon segregation to the dislocation core had progressed over time by aging at room temperature and 


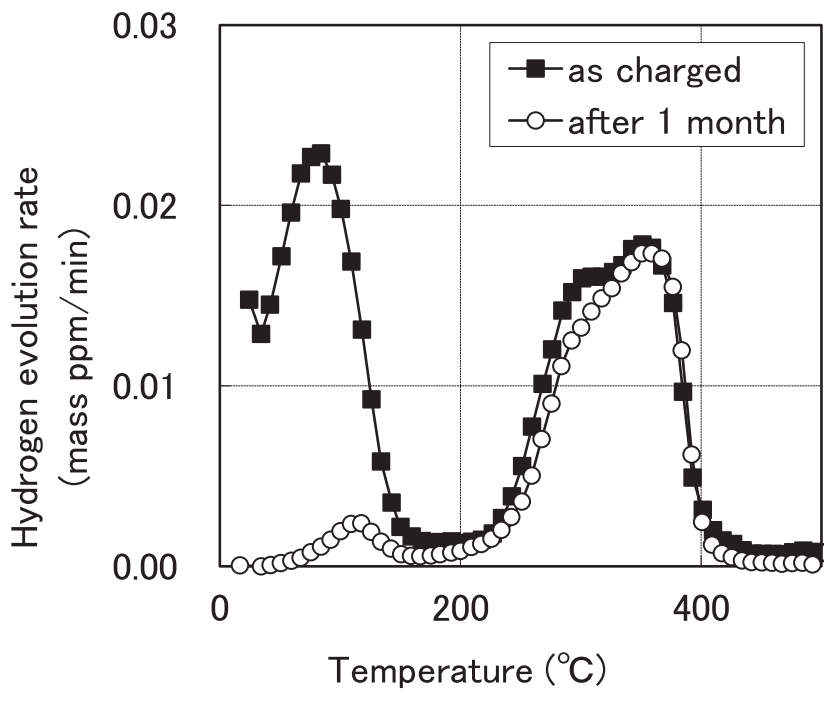

Fig. 1. Hydrogen thermal desorption analysis (TDA) curves for 0.8 mass $\%$ C pearlitic steel drawn at $79.0 \%$ at room temperature together with that after aging at room temperature for 1 month.

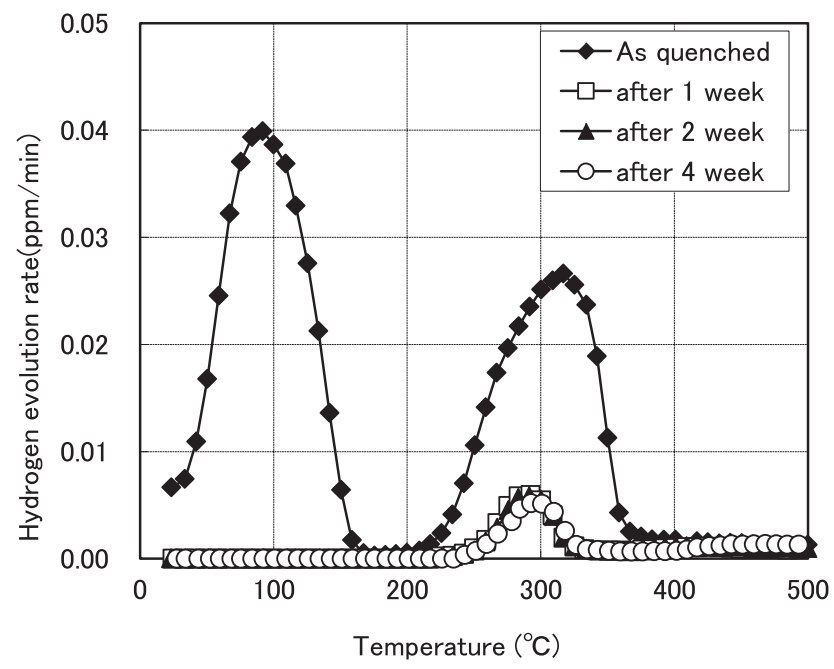

Fig. 2. Changes in TDA curves with aging at room temperature of 0.8 mass $\% \mathrm{C}$ steel annealed at $950^{\circ} \mathrm{C}$ in hydrogen atmosphere followed by quenching.

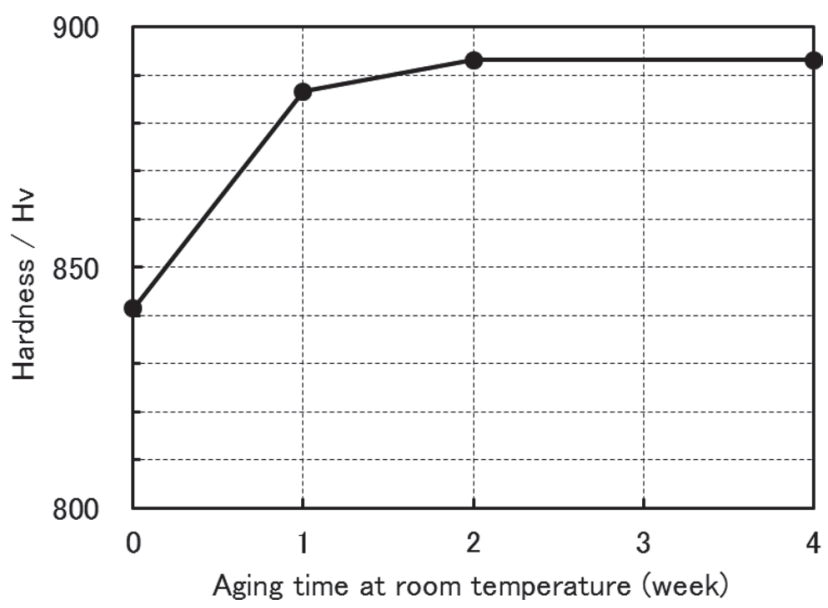

Fig. 3. Changes in Vickers hardness with aging at room temperature of 0.8 mass $\% \mathrm{C}$ steel annealed at $950^{\circ} \mathrm{C}$ in hydrogen atmosphere followed by quenching.

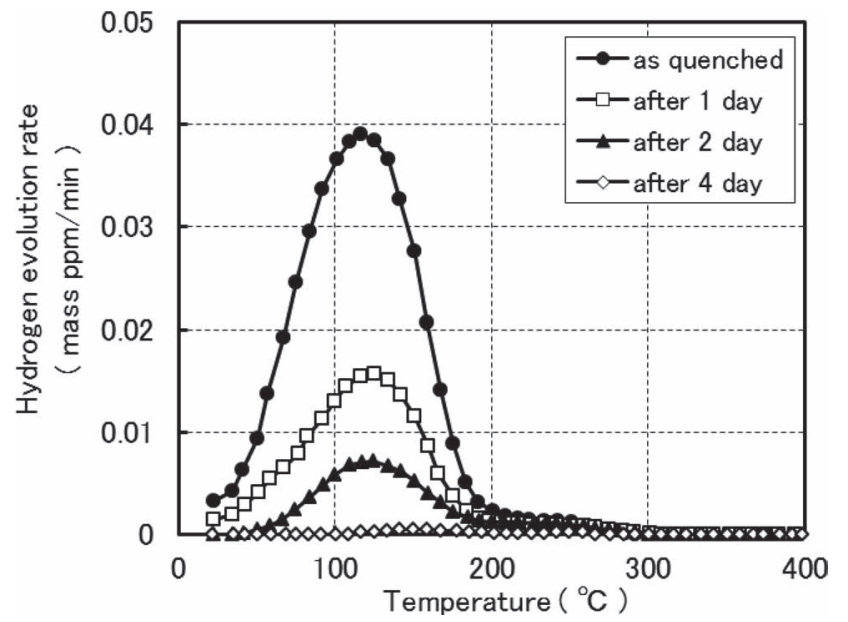

Fig. 4. Changes in TDA curves with aging at room temperature of 0.35 mass $\% \mathrm{C}$ steel annealed at $950^{\circ} \mathrm{C}$ in hydrogen atmosphere followed by quenching.

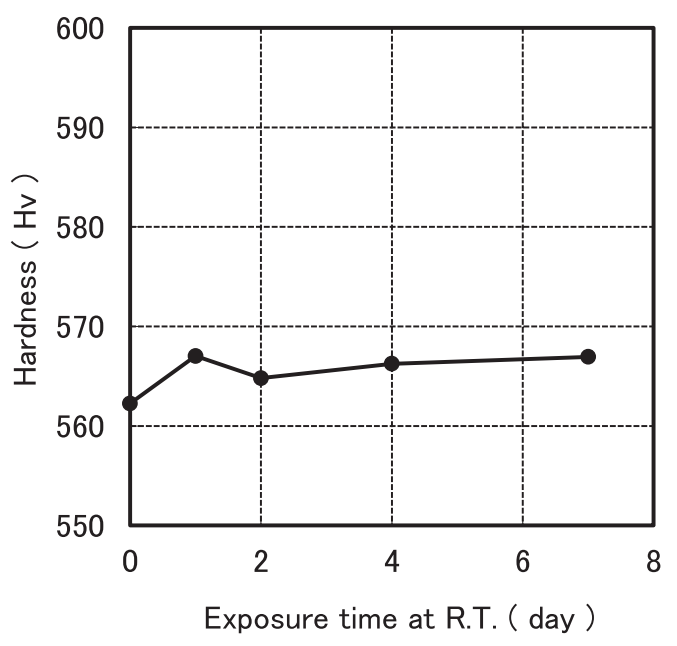

Fig. 5. Changes in Vickers hardness with aging at room temperature of 0.35 mass $\% \mathrm{C}$ steel annealed at $950^{\circ} \mathrm{C}$ in hydrogen atmosphere followed by quenching.

reached saturation in about two weeks.

\subsection{Change of Existing State of Hydrogen in Hydrogen Atmosphere As-quenched 0.35 mass\% C Steel}

The hydrogen TDA curve of SCM435 (0.35 mass\% C steel) annealed at $950^{\circ} \mathrm{C}$ in hydrogen atmosphere of 1 atm followed by oil quenching is shown in Fig. 4. Not like 0.8 mass \% C steel, with 0.35 mass \% C steel and immediately after quenching, only the first peak of hydrogen at $100^{\circ} \mathrm{C}$ was observed and a second peak at $300^{\circ} \mathrm{C}$ was no longer observed. Moreover, hydrogen of the first peak decreased with the increase in aging time. Because the hydrogen of the first peak was trapped weakly in the stress field generated by dislocation, it was considered to have diffused readily at room temperature and disengaged from the surface layer.

Changes in hardness with aging at room temperature of SCM435 (0.35 mass\% C steel) annealed at $950^{\circ} \mathrm{C}$ in hydrogen atmosphere of $1 \mathrm{~atm}$ followed by oil quenching is shown in Fig. 5. In this case, no hardness change was observed with aging at room temperature. It suggests that, because age-hardening due to carbon segregation to the dislocation core with aging has no time-dependence, car- 
bon segregation to dislocation presumably occurred during quenching. The above conjecture corresponds, as shown in Fig. 4, to the fact that the TDA curve of as-quenched material had no second peak at $300^{\circ} \mathrm{C}$, which is the peak of hydrogen trapped in the dislocation core.

\section{Discussion}

The first peak of hydrogen at $100^{\circ} \mathrm{C}$ is observed with as-quenched 0.35 mass $\%$ and 0.8 mass $\% \mathrm{C}$ steels and also with drawn-wire 0.8 mass $\% \mathrm{C}$ steel, which is presumed to be the hydrogen trapped by vacancy or the stress field generated by dislocation as explained by Takai et al. ${ }^{10)} \mathrm{On}$ the other hand, the second peak of hydrogen at $300^{\circ} \mathrm{C}$ is not observed with as-quenched martensitic steel of 0.35 mass $\%$ $\mathrm{C}$, but with drawn-wire pearlitic steel of 0.8 mass $\% \mathrm{C}$ and as-quenched steel of 0.8 mass $\% \mathrm{C}$. Moreover, with aging at room temperature, as-quenched material of 0.8 mass $\%$ $\mathrm{C}$ steel hardened, in contrast, the hydrogen amount of the second peak decreased. Therefore, hydrogen of the second peak is, as Enomoto et al. ${ }^{7)}$ pointed out, is presumed to be trapped in the dislocation core. As described below, it was verified by taking into consideration the dislocation density of martensite and also the diffusion of hydrogen and carbon during quenching that such hydrogen at the $300^{\circ} \mathrm{C}$ peak was the hydrogen trapped in dislocation core.

Figure 6 schematically illustrates the arrangement of dislocation, hydrogen and carbon in martensitic structure. Here, carbon content of as-quenched martensite corresponds to $0.35 \mathrm{mass} \%$ and $0.8 \mathrm{mass} \%$ used in this experiment, and hydrogen content of 3.0 mass ppm, which is the analysis value derived from the TDA method, was adopted. As the dislocation density, $10^{16} / \mathrm{m}^{2}$, which is generally used for martensitic steel, was adopted. Assuming that dislocation of such dislocation density is uniformly distributed, mean inter-dislocation spacing should be $10 \mathrm{~nm}$. Instead, the average inter-atomic distance of hydrogen is $4.06 \mathrm{~nm}$ and that of carbon is $0.680 \mathrm{~nm}$ at carbon content of 0.80 mass $\%$ and $0.897 \mathrm{~nm}$ at $0.35 \mathrm{mass} \%$. Accordingly, the distance between hydrogen and dislocation should be $2.03 \mathrm{~nm}$, and the distance between carbon and dislocation should be $0.340 \mathrm{~nm}$ at $0.80 \mathrm{mass} \%$ and $0.449 \mathrm{~nm}$ at $0.35 \mathrm{mass} \%$.

Because the dislocation is introduced during martens- itic transformation, diffusion coefficients of hydrogen and carbon nearby martensitic transformation start temperature $(M s)$ are important in order to verify the trapping of interstitial solute element to the dislocation core. Then, diffusion must be examined taking the dislocation effect on diffusion into consideration. More specifically, diffusion coefficient $\left(D_{\mathrm{a}}\right)$ in case of the body diffusion, which does not use dislocation, is represented by Eq. (1);

$$
D_{\mathrm{s}}=D_{0} \exp (-Q / R T)
$$

Where, $D_{0}$ equals to $1.24 \times 10^{-5}\left(\mathrm{~m}^{2} / \mathrm{s}\right)$, and $Q$ is the activation energy of diffusion.

Diffusion, which uses the dislocation effect $\left(D_{\mathrm{d}}\right)$, is represented by Eq. (2); ${ }^{19)}$

$$
D_{\mathrm{d}}=D_{0} \exp (-Q / R T) /\left\{1-K_{\mathrm{d}}+K_{\mathrm{d}} \exp (-E / R T)\right\} \ldots
$$

Where, $K_{\mathrm{d}}$ : density of trap site $\left(=\pi r^{2} \rho\right), \rho$ : dislocation density $\left(1 \times 10^{16} / \mathrm{m}^{2}\right), r$ : segregation diameter on dislocation $(=$ $\left.1.0 \times 10^{-9} / \mathrm{m}\right), E_{\mathrm{d}}$ : interaction energy between dislocation and interstitial solute element $(=27 \mathrm{~kJ} / \mathrm{mol}) .{ }^{19)}$ Here, $E_{\mathrm{d}}$ corresponds to trap energy in the stress field generated by dislocation.

Temperature dependence of diffusion coefficient taking the effect of dislocation into consideration is shown in Fig. 7. Carbon has a smaller diffusion coefficient than hydrogen at each temperature, and the difference becomes significantly large at low temperature less than $300^{\circ} \mathrm{C}$.

The above described conditions for diffusion of hydrogen and carbon to reach dislocation in terms of temperature and time is shown in Fig. 8. Here, diffusion distance of hydrogen and carbon was derived from $\left(2 D_{\mathrm{d}} \mathrm{t}\right)^{1 / 2}$ using $D_{\mathrm{d}}$ obtained above. In this case, because the $M s$ temperature estimated by the equation according to Andrew ${ }^{20)}$ is about $340^{\circ} \mathrm{C}$ with 0.35 mass $\%$ steel, both hydrogen and carbon reach dislocation almost at the same time. Since the interaction energy of hydrogen and carbon to dislocation ${ }^{16)}$ is $42 \mathrm{~kJ} / \mathrm{mol}^{21)}$ and $63.6 \mathrm{~kJ} / \mathrm{mol}^{22)}$ respectively, it is expected that carbon has already been trapped in the dislocation core at the time of quenching in case of 0.35 mass $\% \mathrm{C}$ steel.

On the other hand, $M s$ temperature is presumed to be about $220^{\circ} \mathrm{C}$ with 0.80 mass $\% \mathrm{C}$ steel, which is about $120^{\circ} \mathrm{C}$ lower than 0.35 mass $\% \mathrm{C}$ steel. Therefore, as is clearly understood by Fig. 8, hydrogen is expected to arrive faster

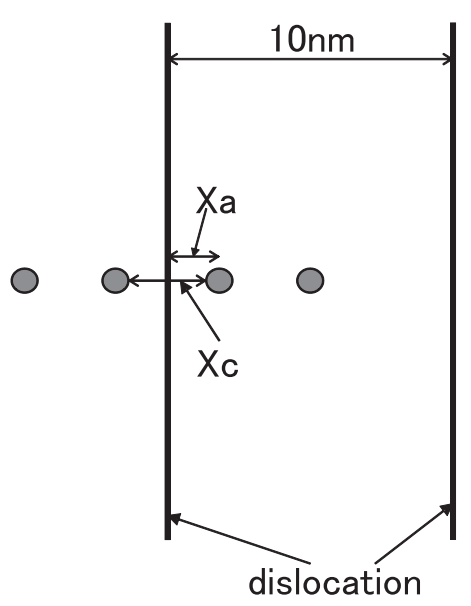
Dislocation density : $10^{16} / \mathrm{m}^{2}$
Mean inter-dislocation spacing : $\ell=\rho^{-1 / 2}=10 \mathrm{~nm}$
Inter-atomic distance $\left(X_{c}\right)$ :
$\mathrm{H} \quad: 4.06 \mathrm{~nm}$
$\mathrm{C}(0.35 \% \mathrm{C}) \quad: 0.897 \mathrm{~nm}$
$\mathrm{C}(0.80 \% \mathrm{C}) \quad: 0.680 \mathrm{~nm}$

Distance between $\mathrm{H}, \mathrm{C}$ and dislocation $(\mathrm{Xa})$ :

$\begin{array}{ll}\mathrm{H} & : 2.03 \mathrm{~nm} \\ \mathrm{C}(0.35 \% \mathrm{C}) & : 0.449 \mathrm{~nm} \\ \mathrm{C}(0.80 \% \mathrm{C}) & : 0.340 \mathrm{~nm}\end{array}$

Fig. 6. Schematic illustration showing the arrangements of dislocations, and interstitial atoms such as hydrogen and carbon in martensite assuming their uniform distributions. 


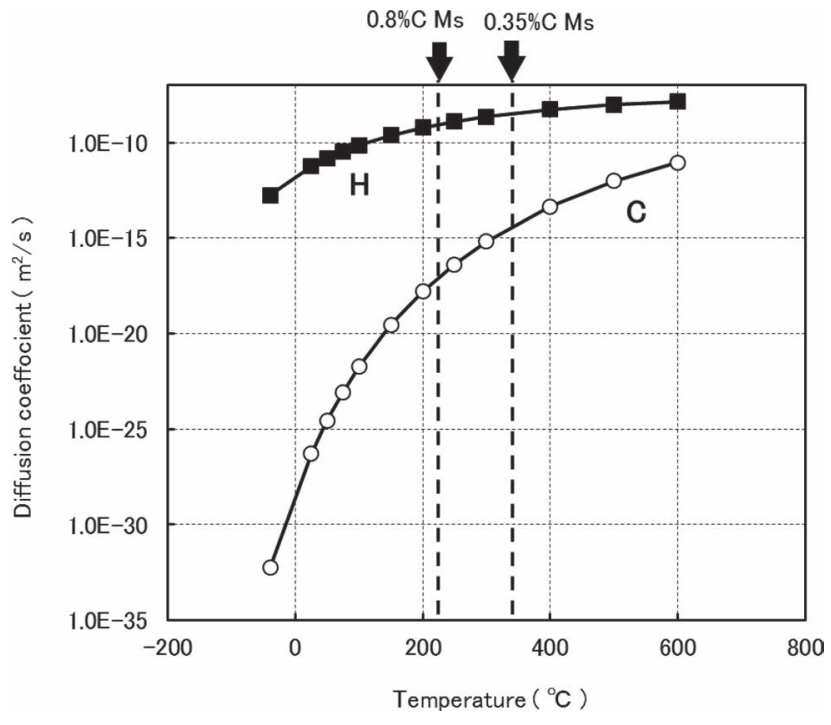

Fig. 7. Temperature dependence of diffusion coefficients of hydrogen and carbon taking into consideration the effect of dislocation.

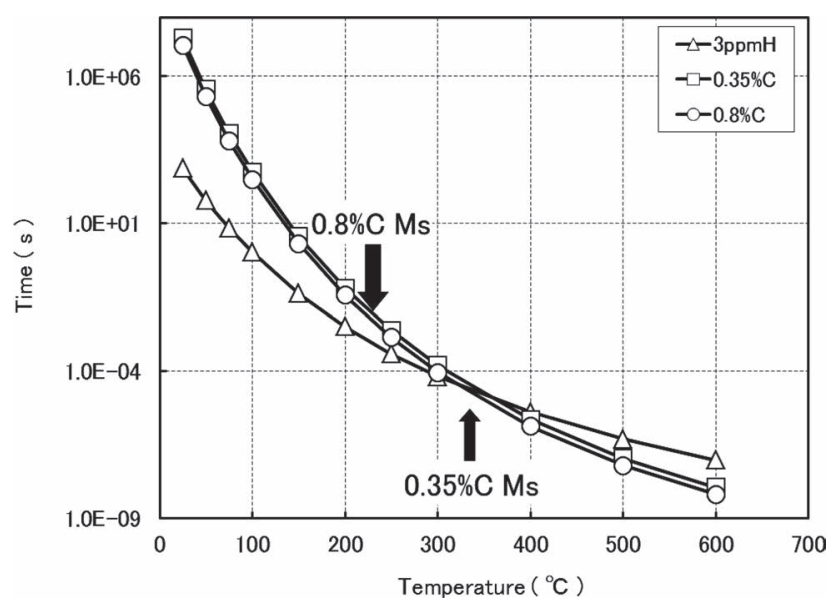

Fig. 8. Conditions for diffusion of hydrogen and carbon to reach dislocation in terms of temperature and time.

at the dislocation core at the time of quenching. However, with aging at room temperature, it is considered that carbon diffused around dislocation replaces hydrogen trapped in the dislocation core because it has higher interaction energy than hydrogen. Therefore, with aging at room temperature, it is expected that the hydrogen amount of the second peak decreases and, conversely, hardness increases by the gradual replacement from hydrogen to carbon.

The above discussion is schematically illustrated in Figs. 9 and 10. The steels with 0.35 mass $\%$ and 0.80 mass $\% \mathrm{C}$ have different $M s$ temperatures. With 0.35 mass\% $\mathrm{C}$ steel which has higher $M s$ temperature, because both hydrogen and carbon reach around dislocation at about the same time, the dislocation core is almost completely occupied by carbon also with as-quenched material. As a result, it is presumed that the hydrogen at the $300^{\circ} \mathrm{C}$-peak was not observed even with as-quenched material (Fig. 9(a)). Because of this, it is also presumed that no hardness change has occurred with aging at room temperature.

On the other hand, because $M s$ temperature is lower with 0.80 mass $\% \mathrm{C}$ steel, hydrogen arrives faster and is trapped
(1) High Ms temp. (0.35mass $\%$ C) Time that solute carbon to reach dislocation is long.

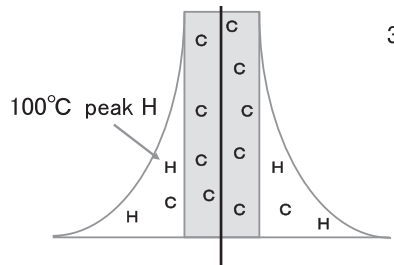

(2) Low Ms temp. (0.80mass\%C) Time that solute carbon to reach dislocation is short-

Fig. 9. Schematic illustration of hydrogen trapping and carbon segregation at dislocation core in steel with different $\mathrm{Ms}$ temperatures; a) 0.35 mass $\% \mathrm{C}$ martensitic steel with high Ms temperature, and b) 0.8 mass $\% \mathrm{C}$ martensitic steel with low Ms temperature. (1) As Quenched
Carbon is supersaturated in the
matrix

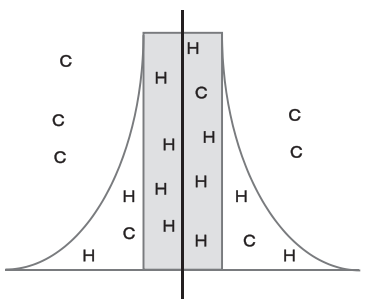

(2) Room temperature aging Carbon reached dislocation, and hydrogen is replaced by carbon

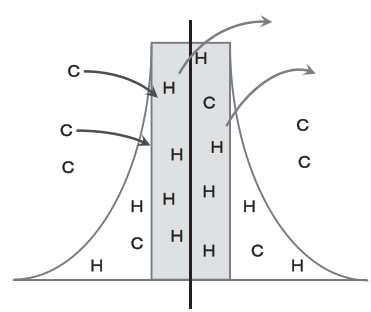

Fig. 10. Schematic illustration showing the change in segregated atoms in dislocations with aging at room temperature of 0.8 mass \% C martensitic steel; a) just after quenching, b) after aging at room temperature following quenching for a longer period.

by the dislocation core immediately after quenching, therefore it is considered to be detected as hydrogen of the second peak of the hydrogen TDA curve at $300^{\circ} \mathrm{C}$ (Fig. 9(b)). However, as-quenched martensite contains carbon in supersaturated solid solution state in its matrix, which diffuses to dislocation with aging at room temperature and, as shown in Figs. 10(a) and 10(b), it is presumed to cause decrease of hydrogen amount at the $300^{\circ} \mathrm{C}$-peak and increase of hardness by replacing hydrogen trapped in the dislocation core.

With drawing-wire of 0.80 mass $\% \mathrm{C}$ steel, hydrogen trapped in the stress field generated by dislocation and the dislocation core introduced by the drawing process is observed at $100^{\circ} \mathrm{C}$ and $300^{\circ} \mathrm{C}$, respectively. Because the hydrogen at the $100^{\circ} \mathrm{C}$-peak is trapped in weak trap sites like as-quenched martensite, it is considered to have decreased as a result of diffusion and discharge from the surface with aging at room temperature. On the other hand, the hydrogen trapped in the dislocation core is, not like as-quenched martensite, because hardly any solute carbon exists with pearlitic steel, the peak at $300^{\circ} \mathrm{C}$ did not decrease even after aging at room temperature. Since such amount of solute carbon differs greatly between drawn-wire pearlite of 0.80 mass $\%$ C steel and as-quenched martensitic steel, it is presumed to cause the significantly different behavior of hydrogen at the $300^{\circ} \mathrm{C}$-peak in regard to aging at room temperature.

\section{Conclusion}

By using drawn-wire pearlitic 0.8 mass $\% \mathrm{C}$ steel charged 
with electrolytic hydrogen and as-quenched 0.8 mass $\% \mathrm{C}$ steel annealed at $950^{\circ} \mathrm{C}$ in hydrogen atmosphere, and asquenched 0.35 mass $\% \mathrm{C}$ steel annealed in hydrogen atmosphere, the change in hydrogen existing state with aging at room temperature was examined by means of thermal desorption analysis (TDA) and hardness measurement to clarify the following facts:

(1) With drawn-wire pearlitic steel with 0.8 mass $\% \mathrm{C}$, hydrogen of both the $100^{\circ} \mathrm{C}$-peak and the $300^{\circ} \mathrm{C}$-peak were observed after electrolytic hydrogen charge, and only the hydrogen of the $100^{\circ} \mathrm{C}$-peak decreased with aging at room temperature.

(2) With the 0.8 mass $\% \mathrm{C}$ steel heated and quenched in hydrogen atmosphere, hydrogen of both the $100^{\circ} \mathrm{C}$-peak and the $300^{\circ} \mathrm{C}$-peak were observed immediately after quenching, and hydrogen of both the $100^{\circ} \mathrm{C}$-peak and the $300^{\circ} \mathrm{C}$-peak decreased with aging at room temperature. Moreover, hardness increased with aging at room temperature, and this increase of hardness saturated in one week.

(3) On the other hand, with the 0.35 mass $\% \mathrm{C}$ steel heated and quenched in hydrogen atmosphere, only the hydrogen of the $100^{\circ} \mathrm{C}$-peak was observed immediately after quenching, and hydrogen of the $100^{\circ} \mathrm{C}$-peak decreased with aging at room temperature and disappeared after four days. Moreover, the change of hardness with aging at room temperature was not observed.

(4) From the above experimental results;

a) The first peak at about $100^{\circ} \mathrm{C}$ is attributed to the hydrogen trapped by the stress field generated by dislocation, and the second peak at about $300^{\circ} \mathrm{C}$ is hydrogen trapped in the dislocation core.

b) In case of 0.35 mass $\% \mathrm{C}$ martensitic steel with high $M s$ temperature, because hydrogen segregated in the dislocation core is replaced by carbon segregation during quenching, the second peak was no longer observed even with asquenched material and hardness change did not occur with aging at room temperature.

c) On the other hand, because 0.8 mass $\% \mathrm{C}$ martensitic steel has low $M s$ temperature, diffusion of carbon to dislocation is insufficient with as-quenched material, therefore hydrogen is considered to have existed in the dislocation core. Moreover, carbon diffused with aging at room-temperature and replaced hydrogen, therefore the second peak decreased over aging time and hardening by aging was also observed.

d) It is presumed that, because hardly any solute carbon existed in drawn-wire pearlitic steel, no significant change of the second peak was observed with aging at roomtemperature.

\section{REFERENCES}

1) S. Matsuyama: Okurehakai, Nikkan Kogyou Shinbunsya, Tokyo, (1989), 70.

2) N. Abe, K. Suzuki, Y. Hagiwara and K. Takai: CAMP-ISIJ, 24 (2011), 926, CD-ROM.

3) H. G. Lee and J-Y. Lee: Acta Metall., 32 (1984), 131.

4) H. Yaguchi, T. Kochi, M. Nomura and T. Watanabe: J. Jpn. Inst. Met., 71 (2007), 781.

5) M. Nagumo: Suisozeika-no-Kiso, Uchida Roukakuho, Tokyo, (2008), 299.

6) H. Hagi: Materia Jpn., 33 (1994), 1407.

7) E. Enomoto, D. Hirakami and T. Tarui: Metall. Mater. Trans. A, 43A (2012), 572

8) T. Tarui and S. Yamasaki: Tetsu-to-Hagané, 88 (2002), 612.

9) J. Takahashi, K. Kawakami, Y. Kobayashi and T. Tarui: Scr. Mater., 63 (2010), 261.

10) T. Takai, G. Yamauchi, M. Nakamura and M. Nagumo: J. Jpn. Inst. Met., 62 (1998), 267.

11) H. Matsui, A. Kimura and H. Kimura: Strength Metals Alloys, 2 (1979), 977

12) S. Asano, Y. Nishino and M. Otsuka: J. Jpn. Inst. Met., 43 (1979), 241.

13) Y. Tokita, H. Katsumoto, H. Yoshida and M. Nagumo: CAMP-ISIJ, 12 (1999), 546.

14) A. McNabb and P. K. Foster: Trans. TMS-AIME, 227 (1963), 618.

15) A. H. Cotrell and B. A. Bilby: Proc. Phys. Soc., A62 (1949), 49.

16) L. Cheng, M. Enomoto, D. Hirakami and T. Tarui: ISIJ Int., 53 (2013), 131 .

17) H. K. BirnBaum and P. Sofronis: Mater. Soc. Eng. A, 176 (1994), 191.

18) S. Taketomi, R. Matsumoto and N. Miyazai: JSME M\&M, 2010 Conf., The Japan Society of Mechanical Engineers, Tokyo, (2010), 27.

19) H. Hagi and Y. Hayashi: J. Jpn. Inst. Met., 51 (1987), 24.

20) K. W. Andrews: JISI, 203 (1965), 721.

21) S. Taketomi, R. Matsumoto and N. Miyazaki: Acta Mater., 56 (2008), 3761.

22) E. Clouet, S. Garruchet, H. Nguyen, M. Perez and C. S. Becqart: Acta Mater., 56 (2008), 3450.

$23)$ S. M. Mayers, S. T. Picraux and R. E. Stoltz: J. Appl. Phys., 50 (1979), 5710.

24) K. Kim and S. Pyun: J. Mater. Sci. Lett., 4 (1985), 624.

25) W. Y. Choo and J. Y. Lee: Metall. Mater., 40 (1992), 1357.

26) T. Asaoka, C. Dagberi, M. Aucouturier and J. Galland: Scr. Metall., 11 (1977), 467. 